\title{
Role of Betatrophin and Inflammation Markers in Type 2 Diabetes Mellitus, Prediabetes and Metabolic Syndrome
}

\author{
Erhan Onalan ${ }^{1}$, Ahmet Bozkurt ${ }^{1}$, Mehmet Ferit Gursu², Burkay Yakar ${ }^{3}$ and Emir Donder ${ }^{1}$ \\ ${ }^{1}$ Department of Internal Medicine, Firat University Medical School, Elazig, Turkey \\ ${ }^{2}$ Department of Medical Biochemistry and Clinical Biochemistry, Firat University Medical School, Elazig, Turkey \\ ${ }^{3}$ Department of Family Medicine, Firat University, Medical School, Elazig, Turkey
}

\begin{abstract}
Objective: To determine the association of betatrophin and inflammation factors in metabolic diseases such as diabetes, impaired fasting glucose, impaired glucose tolerance and metabolic syndrome.

Study Design: A cross-sectional, analytical study.

Place and Duration of Study: Firat University Medical School between April 2017 and December 2020.

Methodology: The study included 20 patients with type 2 diabetes mellitus, 20 patients with impaired fasting glucose (IFG), 20 patients with impaired glucose tolerance (IGT), 20 patients with metabolic syndrome (MetS), and a control group consisting of 20 healthy individuals. Anthropometric, fasting serum biochemical data were collected. Circulating betatrophin, and inflammation markers were measured by enzyme-linked immunosorbent assay (ELISA). The association of betatrophin, TNF-alpha, and IL-6 levels between groups were performed with One-way ANOVA and post-hoc Tukey HSD test.

Results: Significantly higher levels of circulating betatrophin were observed in IFG, IGT, And MetS groups compared to healthy controls $(p=0.017)$. There were significantly difference TNF- $\alpha$ levels in IFG, IGT, and MetS groups compared to healthy controls $(p<0.001)$. The levels of IL- 6 were significantly higher in MetS group than healthy controls $(p=0.007)$.

Conclusion: The circulating betatrophin and TNF- $\alpha$ levels were increased in MetS, IFG and IGT. IL- 6 was decreased in MetS compared to the healty controls. Further studies are needed to elucidate the role of betatrophin and inflammatory parameters in the development of T2DM and prediabetic syndromes, whether betatrophin could have clinical applications in the development of new antidiabetic agents.
\end{abstract}

Key Words: Betatrophin, IL-6, TNF-alpha, Metabolic syndrome, Insulin resistance, Diabetes mellitus type 2.

How to cite this article: Onalan E, Bozkurt A, Gursu MF, Yakar B, Donder E. Role of Betatrophin and Inflammation Markers in Type 2 Diabetes Mellitus, Prediabetes and Metabolic Syndrome. J Coll Physicians Surg Pak 2022; 32(03):303-307.

\section{INTRODUCTION}

Type 2 diabetes mellitus (T2DM) is largely related to trends in obesity and sedentary lifestyle, and its frequency is increasing day by day. ${ }^{1}$ Betatrophin is a peptide secreted from liver and adipose tissue. It is called as RIFL, lipacin, protein 8 like angiprotein ANPTL8, and consisting of 198 amino acids, increases beta cell proliferation in mice and improves glucose tolerance. ${ }^{2}$ It has been reported that betatrophin stimulates pancreatic beta cells and increases endogenous insulin secretion.

Correspondence to: Dr. Erhan Onalan, Department of Internal Medicine, Firat University Medical School, Elazig, Turkey

E-mail:drakdeniz@msn.com

Received: April 28, 2021; Revised: November 24, 2021;

Accepted: December 29, 2021

DOI: https://doi.org/10.29271/jcpsp.2022.03.303
As a result of a series of experiments performed on mouse models by Melton and $\mathrm{Yi}^{3}{ }^{3}$ it has been revealed that betatrophin improves glycemic control by causing pancreatic beta cell rise and beta cell mass increase. ${ }^{4}$ With this important property of betatrophin, previous studies argue that it can replace insulin treatment and may be a new hope for diabetes treatment by increasing the number of endogenous insulin producing cells in diabetics. ${ }^{3,5}$ Contrary to the effects highlighted above, some previous studies have suggested that high betatrophin level causes the development of diabetic retinopathy. ${ }^{6-8}$ The relationship between betatrophin and T2DM is still controversial.

Several studies have suggested that adipokines, including TNF$\alpha$, and IL-6, mediate insulin resistance, and the inflammatory response. ${ }^{9,10}$ Disturbances in TNF- $\alpha$ metabolism play a role in metabolic disorders such as obesity and insulin resistance. ${ }^{11}$ Interleukin-6 (IL-6) is a proinflammatory cytokine that induces inflammation and insulin resistance. ${ }^{12}$ A previous study reported that the inflammatory process, which is induced by IL-6, caused chronic diseases such as diabetes, obesity, cancer, and atherosclerosis. ${ }^{13}$ 
As mentioned above, there are conflicting literature data on the effect of betatrophin and inflammatory parameters on the mechanism of insulin resistance. The current study was aimed to determine the association of betatrophin and inflammation factors in metabolic diseases such as diabetes, impaired fasting glucose (IFG), impaired glucose tolerance (IGT) and metabolic syndrome (MetS).

\section{METHODOLOGY}

The study was conducted between April 2017 and December 2020 at Firat University Medical School Elazig, Turkey. The study included 20 patients with type 2 diabetes mellitus, 20 patients with IFG, 20 patients with IGT, 20 patients with MetS, and a control group consisting of 20 healthy individuals. Individuals with signs of infection, those under anti-inflamatory and steroid treatment, malignant disease, rheumatic diseases, chronic renal failure, thyroid diseases, and type 1 diabetes mellitus, were excluded.

Diabetes and prediabetes were diagnosed according to the American Diabetes Association (ADA) criteria. T2DM was diagnosed based on either the fasting plasma glucose (FPG) of $\geq 126$ $\mathrm{mg} / \mathrm{dL}(7.0 \mathrm{mmol} / \mathrm{L})$ or 2 -hour $\mathrm{PG} \geq 200 \mathrm{mg} / \mathrm{dL}(11.1 \mathrm{mmol} / \mathrm{L})$ during OGTT orglycated hemoglobin $(\mathrm{HbAlc}) \geq 6.5 \%(48 \mathrm{mmol} /-$ mol), or in a patient with classic symptoms of hyperglycemia or hyperglycemic crisis, a random plasma glucose $\geq 200 \mathrm{mg} / \mathrm{dL}$ (11.1 mmol/L). IFG is defined as FPG levels from 100 to 125 $\mathrm{mg} / \mathrm{dL}$ (from 5.6 to $6.9 \mathrm{mmol} / \mathrm{L}$ ) and IGT as 2-hour PG during 75-g OGTT levels from 140 to $199 \mathrm{mg} / \mathrm{dL}$ (from 7.8 to $11.0 \mathrm{mmol} / \mathrm{L}$ ). ${ }^{14}$ In addition to fasting and postprandial plasma glucose to evaluate glycemic control, $\mathrm{HbAlc}$ levels, fasting serum insulin, Cpeptide concentration, metabolic parameters to evaluate pancreatic $\beta$ cell function; serum lipid (total cholesterol, HDL, LDL, VLDL cholesterol, triglyceride) levels were measured. The insulin resistance of the participants was calculated with HOMAIR formula.

Other blood samples were taken into aprotinin tubes. The blood samples taken into these tubes were centrifuged at $3500 \mathrm{rpm}$ for 5 minutes within half an hour and their serums were separated.

Statistical analysis of the data was performed using the IBM SPSS 22 statistics package programme. The Shapiro-Wilk test was used to determine whether the data showed normal distribution. Descriptive statistics of the data were expressed as mean \pm standard deviation for variables with normal distribution in continuous data and median (IQR: $25^{\text {th }}$ percentile- $75^{\text {th }}$ percentile) for variables with non-normal distribution, the frequency for categorical variables as percentage (n [\%]). Categorical variables were compared using Chi-squared tests. In comparison of more than two independent groups, One-way ANOVA and Tukey HSD tests for post-hoc analysis were used for normally distributed continuous data and Kruskal-Wallis $\mathrm{H}$ test with Dunn-Bonferroni post-hoc analysis were used for non-normally distributed continuous data. A value of $p<0.05$ was considered statistically significant.

\section{RESULTS}

This study was conducted on 100 individuals including four patient groups and the control group. In the study, $68 \%$ of the individuals were women and $32 \%$ were men. There was a significant difference in fasting glucose and postprandial glucose, triglyceride, LDL and $\mathrm{HbAlc}$ levels between the patient groups and the control group $(p<0.05)$. There was no significant difference found among serum ALT, creatinine and urea levels $(p>0.05)$. The groups were found to be similar in terms of gender and age ( $p>0.05)$. A significant difference found among groups in terms of BMI. Compared to the control group, there was a significant increase in BMI in T2DM, IGT and MS groups ( $p<0.001)$. The groups were found to be similar in terms of educational status and family history of DM ( $p>0.05$, Table I).

A comparison of biochemical parameters among all groups was shown in Table II. HbA1c, FBG, and PPG levels were higher in MS and T2DM groups than in the control group ( $p<0.001$ ). Triglyceride and LDL levels were higher in the MS group than in the control group ( $p<0.001$ ). PPG level was higher in the IGT group than in the control group ( $p<0.001$, Table II).

Significantly higher levels of circulating betatrophin were observed in IFG, IGT, and MetS groups, compared to healthy controls $(p=0.017)$. There were significant difference in TNF- $\alpha$ levels in IFG, IGT, and MetS groups, compared to healthy controls $(p<0.001)$. The levels of IL- 6 were significantly higher in MetS group than healthy controls ( $p=0.007$, Table III).

\section{DISCUSSION}

The current study revealed that IFG and IGT patients had significantly higher serum betatrophin levels than healthy controls. This result suggests that betatrophin may be a predictive marker in prediabetes and T2DM. Prediabetes is the period before diabetes mellitus. The conversion rates of these patients to diabetes are quite high. In this study, an increased betatrophin levels are observed in stages such as IFG and IGT, which are the early stages of T2DM. However, betatrophin level decreased in patients with T2DM, compared to patients with IFG and IGT. Contrary to this study, it has been shown that serum betatrophin levels are high in patients with T2DM in most of the studies conducted to date. ${ }^{6,15,16}$ It was thought that this situation may be due to the use of anti-insulinemic metformin and insulin injections used patients with T2DM. Most of the patients in these patient groups were using metformin, while six patients were using insulin in addition to metformin. When compared with the literature, it has been stated that metformin decreases betatrophin levels and this result supports the present study. ${ }^{15}$ Serum betatrophin levels were found to be higher in patients with metabolic syndrome than healty controls. However, serum triglyceride levels were higher in MetS patients than control group. This finding suggests that there may be an interaction between serum triglyceride level and betatrophin level. Thus, future studies should focus on this relationship. 


\begin{tabular}{|c|c|c|c|c|c|c|}
\hline & $\begin{array}{l}\text { IFG } \\
\text { n (\%) }\end{array}$ & $\begin{array}{l}\text { IGT } \\
\text { n (\%) }\end{array}$ & $\begin{array}{l}\text { MetS } \\
\text { n (\%) }\end{array}$ & $\begin{array}{l}\text { T2DM } \\
\text { n (\%) }\end{array}$ & $\begin{array}{l}\text { Control } \\
\text { n (\%) }\end{array}$ & p \\
\hline \multicolumn{7}{|l|}{ Gender } \\
\hline Female & $14(70.0)$ & $15(75.0)$ & $15(75.0)$ & $8(40.0)$ & $16(80.0)$ & \multirow{2}{*}{-0.050} \\
\hline Male & $6(30.0)$ & $5(25.0)$ & $5(25.0)$ & $12(60.0)$ & $4(20.0)$ & \\
\hline \multicolumn{7}{|l|}{ Glucosuria } \\
\hline Yes & $0(.0)$ & $1(5.0)$ & $8(40.0)$ & $10(50.0)$ & $0(.0)$ & \multirow{2}{*}{$<0.001$} \\
\hline No & $20(100.0)$ & $19(95.0)$ & $12(60.0)$ & $10(50.0)$ & $20(100.0)$ & \\
\hline \multicolumn{7}{|l|}{ Education status } \\
\hline Literate & $9(45.0)$ & $8(40.0)$ & $9(45.0)$ & $5(25.0)$ & $6(30.0)$ & \multirow{5}{*}{0.548} \\
\hline Primary school & $6(30.0)$ & $3(15.0)$ & $6(30.0)$ & $2(10.0)$ & $3(15.0)$ & \\
\hline Middle school & $2(10.0)$ & $3(15.0)$ & $3(15.0)$ & $4(20.0)$ & $6(30.0)$ & \\
\hline High school & $2(10.0)$ & $3(15.0)$ & $2(10.0)$ & $6(30.0)$ & $4(20.0)$ & \\
\hline University & $1(5.0)$ & $3(15.0)$ & $0(.0)$ & $3(15.0)$ & $1(5.0)$ & \\
\hline \multicolumn{7}{|l|}{ Family history of DM } \\
\hline Yes & $7(35.0)$ & $8(40.0)$ & $10(50.0)$ & $11(55.0)$ & $4(20.0)$ & \multirow{2}{*}{-0.181} \\
\hline No & $13(65.0)$ & $12(60.0)$ & $10(50.0)$ & $9(45.0)$ & $16(80.0)$ & \\
\hline Age (yıl). mean \pm sd & $51.9 \pm 6.5$ & $50.2 \pm 9.0$ & $56.1 \pm 3.1$ & $52.3 \pm 6.2$ & $51.3 \pm 6.0$ & $0.056^{* *}$ \\
\hline $\mathrm{BMI}\left(\mathrm{kg} / \mathrm{m}^{2}\right)$ mean $\pm \mathrm{sd}$ & $25.2 \pm 1.7$ & $27.6 \pm 1.5^{\mathrm{a}}$ & $34.9 \pm 3.4^{a}$ & $26.2 \pm 1.4^{a}$ & $23.5 \pm 1.0$ & $<0.001$ \\
\hline
\end{tabular}

\begin{tabular}{|c|c|c|c|c|c|c|}
\hline & $\begin{array}{l}\text { IFG } \\
\text { median } \pm \text { sd }\end{array}$ & $\begin{array}{l}\text { IGT } \\
\text { median } \pm \text { sd }\end{array}$ & $\begin{array}{l}\text { MetS } \\
\text { median } \pm \text { sd }\end{array}$ & $\begin{array}{l}\text { T2DM } \\
\text { median } \pm \text { sd }\end{array}$ & $\begin{array}{l}\text { Control } \\
\text { median } \pm \text { sd }\end{array}$ & $p^{*}$ \\
\hline HbAlc (\%) & $5.4 \pm 0.5$ & $5.5 \pm 0.5$ & $8.1 \pm 1.6^{\mathrm{a}}$ & $8.7 \pm 1.7^{\mathrm{a}}$ & $5.1 \pm 0.4$ & $<0.001$ \\
\hline FBG $(\mathrm{mg} / \mathrm{dL})$ & $112.3 \pm 6.4$ & $98.6 \pm 8.7$ & $166.0 \pm 56.2^{\mathrm{a}}$ & $151.6 \pm 46.5^{a}$ & $86.4 \pm 6.9$ & $<0.001$ \\
\hline PPG $(\mathrm{mg} / \mathrm{dL})$ & $133.2 \pm 19.2$ & $166.4 \pm 14.1^{\mathrm{a}}$ & $258.2 \pm 71.2^{\mathrm{a}}$ & $261.7 \pm 77.6^{a}$ & $98.4 \pm 11.3$ & $<0.001$ \\
\hline Triglyceride $(\mathrm{mg} / \mathrm{dL})$ & $172.7 \pm 167.6$ & $140.7 \pm 60.9$ & $222.4 \pm 101.9^{a}$ & $187.5 \pm 75.9$ & $121.6 \pm 52.1$ & 0.021 \\
\hline LDL (mg/dL) & $100.7 \pm 30.6$ & $132.5 \pm 37.0$ & $155.5 \pm 35.6^{\mathrm{a}}$ & $131.1 \pm 26.0$ & $109.0 \pm 27.6$ & $<0.001$ \\
\hline $\operatorname{ALT}(\mathrm{U} / \mathrm{L})$ & $25.0 \pm 20.5$ & $20.3 \pm 11.0$ & $22.7 \pm 8.7$ & $24.9 \pm 10.2$ & $19.6 \pm 6.4$ & 0.515 \\
\hline Creatinine $(\mathrm{mg} / \mathrm{dL})$ & $0.8 \pm 0.1$ & $0.7 \pm 0.2$ & $0.8 \pm 0.3$ & $0.8 \pm 0.2$ & $0.7 \pm 0.1$ & 0.084 \\
\hline Urea (mg/dL) & $32.6 \pm 9.7$ & $33.6 \pm 10.9$ & $34.0 \pm 8.4$ & $35.3 \pm 11.4$ & $26.9 \pm 5.6$ & 0.055 \\
\hline
\end{tabular}

syndrome, T2DM: Type 2 diabetes mellitus, PPG: Post-prandial glucose.

Table III: Distribution of betatrophin, TNF- $\alpha$ and IL-6 values by groups.

\begin{tabular}{|l|l|l|l|l|l|l|}
\hline & $\begin{array}{l}\text { IFG } \\
\text { median (IQR) }\end{array}$ & $\begin{array}{l}\text { IGT } \\
\text { median (IQR) }\end{array}$ & $\begin{array}{l}\text { MetS } \\
\text { median (IQR) }\end{array}$ & $\begin{array}{l}\text { T2DM } \\
\text { median (IQR) }\end{array}$ & Control median (IQR) & p $^{*}$ \\
\hline Betatrophin (ng/L) & $334.4(298.9-360.5)^{\mathrm{a}}$ & $334.7(292.9-357.9)^{\mathrm{a}}$ & $295.6(269.4-320.3)^{\mathrm{a}}$ & $320.1(303.4-348.3)$ & $292.4(263.9-312.0)$ & 0.017 \\
\hline TNF- $\alpha(\mathrm{ng} / \mathrm{ml})$ & $1347.4(363.9-11344.6)^{\mathrm{a}}$ & $6873.9(3644.1-8254.5)^{\mathrm{a}}$ & $6621.6(4351.4-7450.5)^{\mathrm{a}}$ & $200.0(122.2-1323.6)$ & $1055.6(731.9-3726.3)$ & $<0.001$ \\
\hline IL-6 $(\mathrm{ng} / \mathrm{L})$ & $202.9(27.6-529.5)$ & $312.4(188.1-437.5)$ & $517.6(417.5-683.3)^{\mathrm{a}}$ & $373.5(32.0-691.1)$ & $248.4(54.0-402.7)$ & 0.007 \\
\hline $\begin{array}{l}{ }^{\circ} \text { Compared to the control group, } p<0.05 ; \\
\text { Type } \text { *Kruskal-Wallis H test; IFG: Impaired fasting glucose, IGT: Impaired glucose tolerance, MetS: Metabolic syndrome, T2DM: }\end{array}$ \\
\hline
\end{tabular}

The current study showed higher BMI levels of patients with MetS and T2DM than of healthy controls. This finding is expected and consistent with literature. ${ }^{5,10}$ Increased serum betatrophin levels in the prediabetic period suggest that betatrophin may have a role in the pathogenesis of T2DM. Novel studies are needed to elucidate the possible role of betatrophin in the pathogenesis of T2DM.

Pro-inflammatory mediators play a crucial role to induce insulin resistance and T2DM via involvement of oxidative stress and the activation of various transcriptional mediated molecular and/or metabolic pathways. Experimental studies have found that pro-inflammatory mediators are interdependently involved to induce tissue-specific inflammation, which may lead to the development of insulin resistance and pathogenesis of T2DM. ${ }^{17}$ The current study showed that TNF- $\alpha$ levels were higher in IFG, IGT, and MetS patients than healthy controls. The previous studies showed that there is low-grade inflammation in the prediabetes stage. ${ }^{18}$ The current study data suggested that this low-grade inflammation plays a role in the pathogenetic processes that cause T2DM.

The current study was found higher IL-6 level in MetS patients than healthy controls. Several studies have suggested that TNF- $\alpha$, and IL- 6 , mediate insulin resistance, and the inflammatory response. ${ }^{19,20}$ The previous study reported that high levels of IL- 6 have been observed in adipose tissues from patients with diabetes mellitus or obesity, particularly those with features of MetS. ${ }^{21}$ According to the obtained results in this study, the authors have thought that changes in TNF- $\alpha$ and IL- 6 levels are a result of diabetes formation stages rather than a causal factor in the transformation of prediabetes stages to T2DM. Insulin resis- 
tance (IR) and b-cell dysfunction include the underlying pathophysiology of prediabetes and its subsequent progression to overt diabetes. Recent studies show that leptin, resistin, IL- 6 and TNF- $\alpha$ play an important role in the emergence of insulin resistance. ${ }^{21}$ In this study, it was found that TNF- $\alpha$ and IL- 6 levels were statistically significantly higher in all stages of prediabetes (BAG, IGT and MetS), compared to the control group. It is seen in the literature that chronically elevated levels of inflammatory biomarkers such as TNF- $\alpha$ and IL- 6 directly cause insulin resistance and impairment of insulin sensitivity and increase the risk of T2DM. ${ }^{19-21}$ The present findings suggest that these cytokines could be used for early diagnosis of diabetes in the future. Because IL- 6 levels were found to be statistically significantly increased in IFG, IGT and MetS patients.

The current study found that elevated betatrophin levels were associated with T2DM and higher BMI. This relationship of betatrophin and T2DM has been previously reported by Fu et al. ${ }^{16}$ Recent reports have shown that a betatrophin transcript variant and its expression levels correlate with clinical or pathological symptoms. The genetic R59W variant of betatrophine has been shown to be associated with the reduction of HDL and LDL in African-American and Spanish participants, and higher levels of circulating betatrophin protein were found in overweight / obese groups in type 2 diabetes patients. ${ }^{22} \mathrm{~A}$ previous study reported that serum betatrophin levels increased significantly in prediabetic stages (IFG-IGT) and T2DM. ${ }^{23}$ These findings were thought that serum betatrophin levels are associated with glucose intolerance. Similar findings by Liu et al., ${ }^{24}$ reported that serum betatrophin levels were higher in T2DM and IGT patients than healthy controls, and it was found to be closely related to insulin resistance. The present findings of Liu et al. also support the above-mentioned hypothesis.

Chen et al. ${ }^{23}$ found that betatrophin levels increased in patients with T2DM. It has also been observed that betatrophine affects the lipid profile and insulin resistance states. There is a significant positive relationship between $\mathrm{HbAlc}$ and triglyceride levels in type 2 diabetic patients. ${ }^{25}$ Proinflammatory cytokine levels and betatrophin and $\mathrm{HbAlc}$ levels are found to be related in a similar way with MetS in the T2DM group, and dyslipidemic values with increased circulating levels of IL- 6 and TNF- $\alpha$ play a role in a cellular balance in prediabetic stages.

The major limitations of this study included its single-centre design, low number of patients, so the current study may face us to can not generalize to other settings in the rest of the country or across the world. Here, the lack of VLDL, total cholesterol, and insulin values in the patient groups in this study was also seen as one of the reasons limiting the results of this study.

\section{CONCLUSION}

The circulating levels of betatrophin and TNF- $\alpha$ were increased in MetS, IFG and IGT. IL-6 was decreased in MetS compared to the healty controls. Further studies are needed to elucidate the role of betatrophin and inflammatory parameters in the development of T2DM and prediabetic syndromes whether betatrophin could have clinical applications in the development of new antidiabetic drugs.

\section{ETHICAL APPROVAL:}

The study protocol was approved by the Ethics Committee of Firat University (No. 05-16, Date: 16/03/2017).

\section{PATIENTS' CONSENT:}

Written informed consents were obtained from all patients. The study was conducted in accordance with the principles of the Declaration of Helsinki.

\section{CONFLICT OF INTEREST:}

The authors declared no conflict of interest.

\section{AUTHORS' CONTRIBUTION:}

EO, AB: Data collection, design, compiling, and discussion. Led and conceived the project, and authored the manuscript.

BY: Collecting and analysing data, discussion.

ED, MFG: Collecting statistics and analysing data.

\section{REFERENCES}

1. Engelgau MM, Geiss LS, Saaddine JB, Boyle J, Benjamın S, Gregg $E$, et al. The evolving diabetes burden in the United States. Ann Intern Med 2004; 140(11):945-50. doi: 10.7326/0003-4819-140-11-200406010-00035.

2. Zhang R. Lipasin, a novel nutritionally-regulated liver-enriched factor that regulates serum triglyceride levels. Biochem Biophys Res Commun 2012; 424(4):786-92. doi: 10.1016/j.bbrc.2012.07.038.

3. Yi P, Park JS, Melton DA. A hormone that controls pancreatic b cell proliferation. Cell 2013; 153(4):747-58. doi: 10.1016/j.cell.2013.04.008.

4. Zhu JZ, Yu CH, Li YM. Betatrophin provides a new insight into diabetes treatment and lipid metabolism. Biomed Rep 2014; 2(4):447-51. doi: 10.3892/br.2014.284.

5. Guo K, Lu J, Yu H, Zhao F, Pan P, Zhang L, et al. Serum betatrophin concentrations are significantly increased in overweight but not in obese or type 2 diabetic individuals. Obesitiy 2015; 23(4):793-97. doi: 10.1002/oby.21038.

6. Wang YY, Zhang D, Jiang ZY, Lu XQ, Zheng X, Yu YJ, et al. Positive association between betatrophin and diabetic retinopathy risk in type 2 diabetes patients. Horm Metab Res 2016; 48(3):169-73. doi: 10.1055/s-0035-1550009.

7. Dong CX, Song CP, Zhang CP, Dong M, Gong XR, Gao HY, et al. Clinical and experimental study on angiopoietin-like protein 8 associated with proliferative diabetic retinopathy. Int J Ophthalmol 2017; 10(12):1819-23. doi: 10.18240/ijo. 2017.12.05.

8. Lu Q, Lu L, Chen W, Lu P. Expression of angiopoietin-like protein 8 correlates with VEGF in patients with proliferative diabetic retinopathy. Graefes Arch Clin Exp Ophthalmol 2017; 255(8):1515-23. doi: 10.1007/s00417-017-3676-z. 
9. Satish M, Saxena SK, Agrawal DK. Adipokine dysregulation and insulin resistance with atherosclerotic vascular disease: Metabolic syndrome or independent sequelae? J Cardiovasc Transl Res 2019; 12(5):415-24. doi: 10.1007/s12265019-09879-0.

10. Groop LC, Saloranta C, Shank M, Bonadonna RC, Ferrannini $E$, Defronzo RA. The role of free fatty acid metabolism in the pathogenesis of insulin resistance in obesity and noninsulindependent diabetes mellitus. J Clin Endocrinol Metab 1991; 72(1):96-107. doi: 10.1210/jcem-72-1-96.

11. Akash MSH, Rehman K, Liaqat A. Tumor Necrosis FactorAlpha: Role in development of insulin resistance and pathogenesis of Type 2 diabetes mellitus. J Cell Biochem 2018; 119(1):105-10. doi: 10.1002/jcb.26174.

12. Rehman K, Akash MSH, Liaqat A, Kamal S, Qadir MI, Rasul A. Role of interleukin- 6 in development of insulin resistance and type 2 diabetes mellitus. Crit Rev Eukaryot Gene Expr 2017; 27(3):229-36. doi: 10.1615/CritRevEukaryot GeneExpr.2017019712.

13. Mauer J, Denson JL, Bruning JC. Versatile functions for IL-6 in metabolism and cancer. Trends Immunol 2015; 36(2): 92-101. doi: 10.1016/j.it.2014.12.008. Epub 2015 Jan 21.

14. American Diabetes Association. Classification and diagnosis of diabetes: Standards of medical care in diabetes-2020. Diabetes Care 2020; 43(1):14-31. doi: 10.2337/dc20-S002.

15. Wang H, Du L, Wu T, Yang G, Hu W, Wang H, et al. Circulating betatrophin is associated with insulin resistance in humans: Cross-sectional and interventional studies in vivo and in vitro. Oncotarget 2017; 8(57):96604-14. doi: 10.18632/oncotarget.21852.

16. Fu Z, Berhane F, Fite A, Seyoum B, Abu-samra AB, Zhang R, et al. Elevated circulating lipasin/ betatrophin in human tip 2 diabetes and obesity. Sci Rep 2014; 4:5013.

17. Rehman K, Akash MS. Mechanisms of inflammatory responses and development of insulin resistance: How are they interlinked? J Biomed Sci 2016; 23(1):87. doi: 10.1186/ s12929016-0303-y.

18. Akash MS, Rehman K, Chen S. Role of inflammatory mechanisms in pathogenesis of type 2 diabetes mellitus. J Cell Biochem 2013; 114(3):525-31. doi: 10.1002/jcb.24402.

19. Tsai JP. The association of serum leptin levels with metabolic diseases. Ci Ji Yi Xue Za Zhi 2017; 29(4):192-6. doi: 10.4103/tcmj.tcmj_123_17.

20. Kadowaki T, Yamauchi T, Kubota N, Hara K, Ueki K, Tobe K. Adiponectin and adiponectin receptors in insulin resistance, diabetes, and the metabolic syndrome. J Clin Invest 2006; 116(7):1784-92. doi: 10.1172/JCI29126.

21. Rodrigues KF, Pietrani NT, Bosco AA, Campos FMF, Sandrim VC, Gomes KB. IL-6, TNF- $\alpha$, and IL-10 levels/polymorphisms and their association with type 2 diabetes mellitus and obesity in Brazilian individuals. Arch Endocrinol Metab 2017; 61(5):438-46. doi: 10.1590/2359-3997000000254.

22. Abu-farha M, Melhem M, Abubaker J, Elkum N, Alsmadi O, Behbehani K, et al. ANGPTL8/Betatrophin R59W variant is associated with higher glucose level in non-diabetic Arabs in living Kuwaits. Lipids Health Disease 2016; 15:195-6. doi: 10.1186/s12944-016-0195-6.

23. Chen X, Lu P, Zhang J, Yang Y, Zhou X, Liu L, et al. Circulating betatrophin levels are increased in patients with type 2 diabetes and associated with insülin resistance. J Clin Endocrinol Metab 2015; 100(1):96-100. doi: 10.1210/jc. 2014-2300.

24. Li S, Liu D, Li L, Li Y, Li Q, An Z, et al. Circulating betatrophin in patients with type 2 diabetes: A meta-analysis. J Diabetes Res 2016; 2016:6194750. doi: 10.1155/2016/6194750.

25. Naqvi S, Naveed S, Ali Z, Ahmad SM, Asadullah Khan R, Raj $\mathrm{H}$, et al. Correlation between glycated hemoglobin and triglyceride level in type 2 diabetes mellitus. Cureus 2017; 9(6):e1347. doi: 10.7759/cureus.1347. 